\title{
Tritan colour contrast sensitivity function in refractive multifocal intraocular lenses
}

\author{
Stefan Pieh, Georg Hanselmayer, Birgit Lackner, Patrick Marvan, Andreas Grechenig,
} Herbert Weghaupt, Clemens Vass, Christian Skorpik

\begin{abstract}
Aims-To compare tritan colour contrast sensitivity (CCS), without and with glare, in patients with refractive multifocal intraocular lenses (IOLs) and with monofocal intraocular lenses.

Methods-Tritan CCS was determined (Moorfields Vision System, CH Electronics) in 15 eyes (14 patients, $75.7( \pm 6.6)$ years) with a refractive multifocal IOL (Allergan SA 40N) and in 11 eyes (10 patients, $73.7( \pm 6.4)$ years) with a monofocal IOL (Allergan SI 40 NB). Measurements were made monocularly under mesopic conditions at a distance of 2 metres from the monitor with best distance refraction plus $0.5 \mathrm{D}$ at $0.5,1,3,6$, 11.4 , and 22.8 cycles per degree (cpd). The test was then repeated for the multifocal IOLs, adding minus $2.5 \mathrm{D}$ to the best distance refraction to force the patient to use the near focus. Both lenses were also investigated under glare conditions with the same set-up and using the brightness acuity tester (BAT).
\end{abstract}

Results-The tritan CCS function without glare in multifocal lenses through the distance focus was nearly identical to that through the near focus. The following statistically significant differences were measured: the CCS function without glare for the multifocal lens was worse at $0.5 \mathrm{cpd}$ and $1.0 \mathrm{cpd}$ than that of the monofocal lens. In CCS testing of the multifocal group with glare at $6 \mathrm{cpd}$, the results through the distance focus were better than the results through the near focus. For the CCS function with glare, the values for the distance focus in the multifocal lens were worse than the values for the monofocal lens at $0.5 \mathrm{cpd}$ and $1 \mathrm{cpd}$. In CCS testing with glare through the near focus and CCS testing through the monofocal lens, the monofocal lens performed better at $0.5 \mathrm{cpd}, 1 \mathrm{cpd}, 3 \mathrm{cpd}$, and $6 \mathrm{cpd}$. Conclusion-Refractive multifocal intraocular lenses influence tritan CCS function compared to monofocal lenses. (Br F Ophthalmol 2001;85:811-815)

Intraocular multifocal lenses generally have two focal points that create sharp images on the retina of objects at infinity and at reading distance respectively. This property provides the patient with a pseudoaccommodation enabling sharp perception of objects both far away and at reading distance. In between these two object distances the visual acuity remains at approximately Snellen 0.5 because of the increased depth of focus compared with a monofocal lens. ${ }^{1-3}$ In everyday life the pseudoaccommodation gained makes the patient independent of glasses, under the precondition of an exact preoperative biometry. ${ }^{4}$ The theoretical disadvantage of the multifocal concept is that the incoming light is divided between more than one focal point, leading to a reduced "through the focus response function" (TFR). ${ }^{5}$ Moreover, sharp images on the retina are always overlaid by out of focus images generated by coexisting foci. Under the circumstances of everyday life, the patient does not perceive this out of focus image. In contradiction to tests on the optical bench, ${ }^{6-8}$ a large number of clinical tests have revealed that the distance visual acuity is similar to that of monofocal lenses ${ }^{9}$ and that even the black and white contrast sensitivity is comparable ${ }^{1011}$ or only slightly reduced compared with monofocal lenses. ${ }^{12-23}$ However, the visual system deals with colour contrast not for reasons of high spatial discrimination but to enrich the image in the visual scene. ${ }^{24}$ Colour vision results from the differentiation of colour tone, brightness, and saturation. The human eye is able to combine these three aspects to create several million different colours. Furthermore, colour vision is influenced by the wavelength and intensity of the light reflected by the visualised object, by the wavelength and intensity of the background illumination of the object, by the individual "bright-dark adaptation," and by the context in which the object appears for the observer. ${ }^{24}$ In general, the ability to discriminate different colours is a function of the fovea. Three different cone types ${ }^{25}$ defined by three different photopigments are known. The area of the cones reduces colour vision to the fovea and parafoveal region. In the innermost circle of the fovea only green and red cones are present and no blue cones. This circumstance is described as "foveal tritanopia." ${ }^{26} 27$ Furthermore, the relatively lower numbers of S-cones are thought to be responsible for the reduced visual acuity and contrast sensitivity in blue light. ${ }^{29}$ Physiologically, CCS is highest at low spatial frequencies, decreasing continuously at higher spatial frequencies. The colour optic tract differs from the brightness optic tract. CCS describes the ability to perceive an object which has different colours from its background but the same brightness. The ability to discriminate different colours may also be influenced by ocular longitudinal chromatic aberration. ${ }^{30}$

The aim of our investigations was to evaluate how finely blue-yellow contrasts at different spatial frequencies were resolved, without and
Accepted for publication 31 January 2001 
with glare, in patients with refractive multifocal intraocular lenses compared with patients with monofocal lenses.

\section{Patients and methods}

Exclusion criteria for patients were the following: (1) corneal astigmatism over $2 \mathrm{D}$; (2) pathologies of the cornea; (3) pupil diameter at 12 lux under $3 \mathrm{~mm}$; (4) clinically relevant opacification of the posterior capsule; and (5) pathologies of the vitreous and retina which could influence visual acuity.

In the first group, 15 eyes ( 14 patients, 75.7 $( \pm 6.6)$ years, range $63.3-87.1$ ) with a refractive multifocal IOL (SA $40 \mathrm{~N}$, Allergan) were evaluated. The refractive SA $40 \mathrm{~N}$ lens is a biconvex, three piece silicone IOL with polypropylene haptics and a diameter of the optical zone of $6 \mathrm{~mm}$. Five annular aspherical zones, incorporated into the anterior surface, evoke the multifocal function. Each zone consists of a continuous curve of a $3.5 \mathrm{D}$ power range. The central diameter of $2 \mathrm{~mm}$ is mainly used for the distance focus, so that the light distribution varies with pupil size. At a pupil diameter of $4 \mathrm{~mm} 50 \%$ of the light passes to the distance focus, whereas only $35 \%$ is distributed to the near focus and $15 \%$ to the intermediate foci. In the second group, 11 eyes (10 patients, 73.7 ( \pm 6.4 ) years, range 64.1-82.0) were investigated. The SI $40 \mathrm{NB}$ is a monofocal lens made of a highly refractive silicone like the SA $40 \mathrm{~N}$.

Distance visual acuity was determined at a viewing distance of 6 metres by means of a standard Snellen projector (Möller Wedel 1000) with best distance correction. The Panel D 15 test was performed monocularly in the multifocal groups with the best distance refraction using the near focus, and in the monofocal group with the best distance correction plus 3.0 D to exclude patients with a possible colour deficit. Pupil diameter was measured at 12, 170 , and with the brightness acuity tester, 900 lux, with the Goldmann perimeter (HaagStreit) using the integrated millimetre scale. The illumination was monitored using a commercially available luxmeter.

Tritan CCS was evaluated by means of the Moorfields Vision System (CH Electronics). This is a computer system with a special graphic card, an autocalibrating program with a photometer head and the associated software. A flat screen monitor was used with a special surface coating to reduce reflections of all kinds (MultiSync \& 6FGp, NEC). All the tests were performed by three investigators with experience in tritan CCS testing. Flicker fusion photometry was done to exclude the "brightness matching error." 31 First green and red light and then blue and red light flicker were performed at a constant frequency of 15 $\mathrm{Hz}$ until the patient could not (or hardly) observe a flickering. The test was performed in duplicate to check the reliability; in the case of large differences it was repeated. The results of the test were three different colours of different wavelength but the same brightness, that were automatically the basis for the subsequent tests. CCS testing with the Moorfields Vision System was carried out monocularly at a distance of 2 metres from the monitor without dark adaptation. For the first test in the multifocal group, best distance refraction plus $0.5 \mathrm{D}$ for the viewing distance was used. If no refraction was necessary for the patient, glasses were also used to standardise the testing conditions. The magnification effect of $1 \%{ }^{32}$ of the 0.5 plus lens was taken into account when calculating the grating pattern for a viewing distance of 2 metres. Tritan CCS was measured at 0.5, 1, 3, $6,11.4$, and $22.8 \mathrm{cpd}$ using the "forced choice" mode in the Moorfields Vision System. The test started at the lowest spatial frequency of $0.5 \mathrm{cpd}$ with a contrast level to ensure that the grating pattern was clearly visible for the patient. The gratings were nominally isoluminant with alternating blue and yellow bars. In the Moorfields Vision System, the area where the grating appears on the monitor had to be reduced to $15 \times 12 \mathrm{~cm}$ to be able to generate all spatial frequencies. Peripheral to this area, the monitor appears grey. In every introduction of the test, each patient was told that the test required the blue yellow bars to be differentiated, but not the edges of the testing field against the peripheral background. The contrast level in the "forced choice" mode was then reduced in $2 \%$ contrast steps as long as the patient confirmed being able to see the bars. When the bars disappeared for the patient, the contrast level was recorded and the contrast further reduced. The contrast level was then increased again and the patient asked to state when the gratings became visible again. The mean value of these two contrast levels was the threshold result. The evaluated contrast thresholds in percentages were recorded as tritan CCS function results ( $1 /$ contrast) and plotted on a logarithmic scale. ${ }^{33}$ The same procedure took place at all tested spatial frequencies. If the patient could not detect the gratings, the tritan CCS function was defined as zero. Subsequently, the same test was repeated but at best distance refraction plus minus $2.5 \mathrm{D}$ to force the patient to use the near focus. In this case too, enlarging the sinusoidal grating pattern by $5 \%$ equalised the diminution by the minus $2.5 \mathrm{D}$ lens. ${ }^{32}$

For the monofocal group, this test was performed analogously to the through the distance focus testing of the multifocal group.

After this test series had been completed, the tests were repeated using the brightness acuity tester (BAT). The BAT consists of an illuminated hemispherical bowl, $60 \mathrm{~mm}$ in diameter, with a central $12 \mathrm{~mm}$ circular aperture through which the patient can view the gratings. The bowl luminance was set at $300 \mathrm{~cd} / \mathrm{m}^{2}$. The tests were performed as described above for the multifocal group and for the monofocal group.

The Mann-Whitney test (non-parametric test) was used to compare the results within the multifocal group and the results of the multifocal and monofocal group in CCS and CCS with glare.

\section{Results}

In the refractive group the corrected distance visual acuity was $0.94( \pm 0.14)$. Snellen. In the monofocal group distance visual acuity with 
Table 1 Results of colour contrast sensitivity function testing without and with glare in a refractive multifocal IOL (Allergan $S A 40 N$ ) through the distance focus $(n=15)$, through the near focus $(n=15)$ and in a monofocal intraocular lens $(n=11$, Allergan SI $40 \mathrm{NB})$. (cpd $=$ cycles per degree)

\begin{tabular}{|c|c|c|c|}
\hline$c p d$ & SA40N distance focus & SA40N near focus & $S I 40 N B$ \\
\hline \multicolumn{4}{|c|}{ CCS function without glare in refractive multifocal IOLs and monofocal IOLs } \\
\hline 0.5 & $14.59(12.02)$ & $15.09(13.12)$ & $21.37(11.42)$ \\
\hline 1 & $9.45(5.82)$ & $10.15(7.10)$ & $16.20(5.92)$ \\
\hline 3 & $4.24(2.10)$ & $4.22(1.94)$ & $6.76(4.23)$ \\
\hline 6 & $2.97(2.14)$ & $2.26(1.08)$ & $3.63(2.05)$ \\
\hline 11.4 & $0.79(0.75)$ & $0.95(0.81)$ & $1.55(0.94)$ \\
\hline 22.8 & $0.27(0.50)$ & $0.18(0.41)$ & $1.11(0.38)$ \\
\hline \multicolumn{4}{|c|}{ CCS function with glare in refractive multifocal IOLs and monofocal IOLs } \\
\hline 0.5 & $10.37(3.75)$ & $9.55(2.29)$ & $13.79(5.22)$ \\
\hline 1 & $7.68(2.64)$ & $8.04(3.79)$ & $11.02(3.29)$ \\
\hline 3 & $3.66(1.34)$ & $3.06(2.01)$ & $4.50(1.87)$ \\
\hline 6 & $2.02(1.08)$ & $0.94(0.74)$ & $2.19(0.69)$ \\
\hline 11.4 & $0.39(0.57)$ & $0.29(0.52)$ & $1.08(0.79)$ \\
\hline 22.8 & $0.09(0.30)$ & $0.17(0.40)$ & $0.09(0.30)$ \\
\hline
\end{tabular}

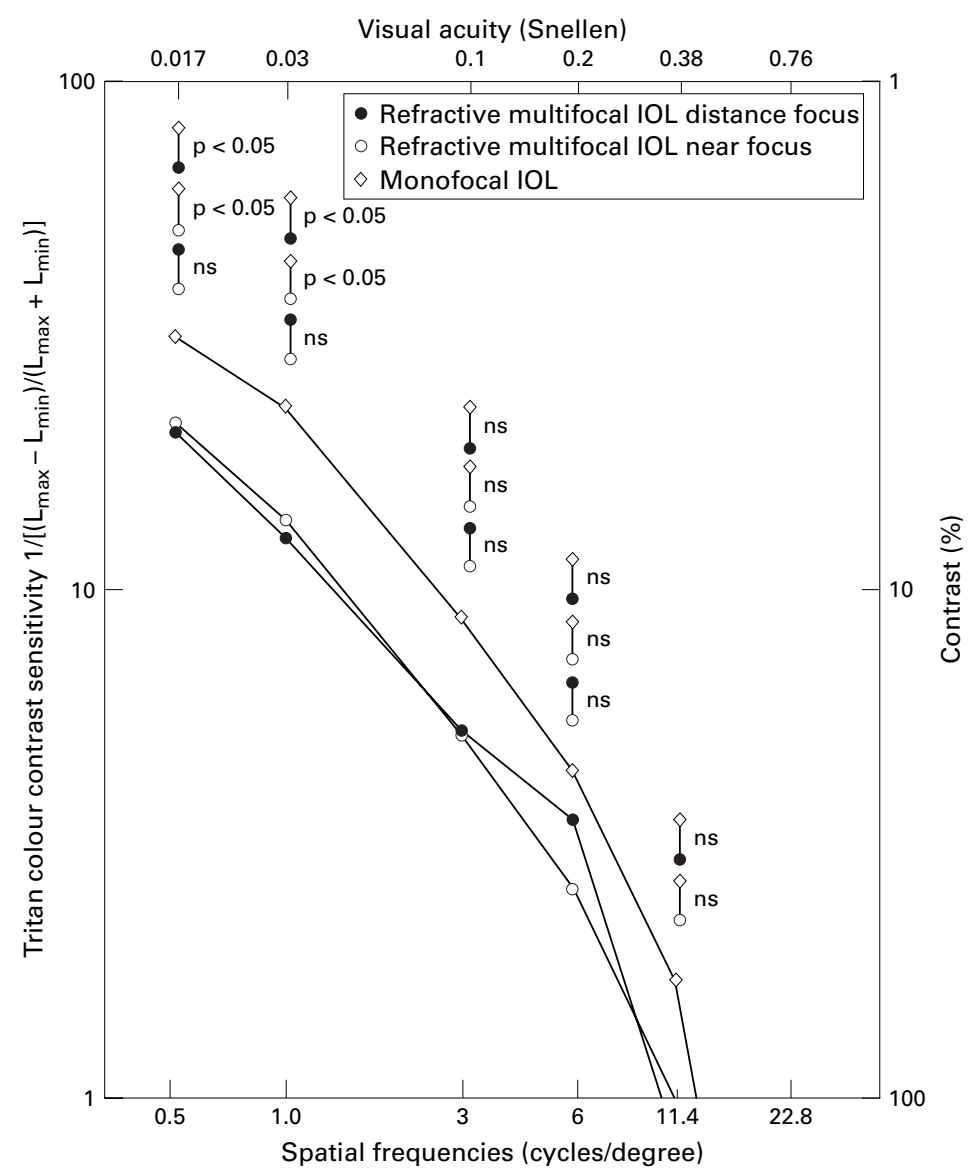

Figure 1 Colour contrast sensitivity function through the distance focus $(n=15)$ in a refractive multifocal IOL (Allergan $S A 40 N$ ), through the near focus $(n=15$ ) in a refractive multifocal IOL (Allergan $S A 40 N$ ), and in a monofocal IOL $(n=11$, Allergan SI $40 \mathrm{NB}$ ). The Mann-Whitney test was calculated between the results for the monofocal group and the distance focus of the multifocal group $(\diamond-\bullet)$, between the monofocal group and the near focus results in the multifocal group $(\diamond-0)$, and between the distance focus and the near focus results ( -1 in the multifocal group ( $n s=$ not significant).

the best distance refraction was $1.0( \pm 0.19)$ Snellen. Mean pupil diameter for both groups was $4.75( \pm 0.97) \mathrm{mm}$ (range $3.9-7.1$ ) at 12 lux, $3.68( \pm 0.69) \mathrm{mm}$ (range $2.9-5.1)$ at 170 lux and $1.13( \pm 0.35) \mathrm{mm}$ (range $0.7-2.5)$ at 900 lux.

Table 1 shows the CCS function results. In Figure 1, the graph of the distance focus was comparable with the graph of the near focus between $0.5 \mathrm{cpd}$ and $6 \mathrm{cpd}$. Statistical evaluations revealed no significant differences at any spatial frequency.
In both tests, the results for the multifocal group were below those for the monofocal group at all spatial frequencies from $0.5 \mathrm{cpd}$ to $11.4 \mathrm{cpd}$; at $0.5 \mathrm{cpd}$ and $1.0 \mathrm{cpd}$ the difference was statistically significant. At $22.8 \mathrm{cpd}$ all three CCS graphs were below 1 .

The results for CCS testing with glare are shown in Table 1. Comparing the CCS function with glare for the two tests in the multifocal group (see Fig 2), the graph for the distance focus is slightly above the graph of the near focus at $0.5 \mathrm{cpd}$, comparable at $1.0 \mathrm{cpd}$ and further above at $3 \mathrm{cpd}$ and $6 \mathrm{cpd}$. At 11.4 cpd and $22.8 \mathrm{cpd}$ both graphs are below 1 . The Mann-Whitney test showed a statistically significant difference at $6 \mathrm{cpd}$.

Both graphs for the multifocal groups remained below the graph for the monofocal group except at $22.8 \mathrm{cpd}$, where all three graphs were below 1. Between group differences were statistically significant at $0.5 \mathrm{cpd}$ and $1 \mathrm{cpd}$ for the results from through the distance focus compared with those for the monofocal lens, and from $0.5 \mathrm{cpd}$ to $6 \mathrm{cpd}$ for the results from the monofocal lens compared with those from near focus testing in the multifocal lens.

\section{Discussion}

Multifocal lenses are so far the only possibility for overcoming the loss of accommodation after cataract surgery. The remarkably good results with multifocal implants in visual acuity led to the hypothesis that the division of incoming light between more than one focus, leading to a retina image of reduced light intensity, ${ }^{5}$ does not affect the visual abilities. One explanation for this might be that in most cases enough light is available for image creation as a result of the high sensitivity of the retina. The fact that focal points are situated behind each other in multifocal intraocular lenses results in the sharp image being overlaid by out of focus images on the retina. In everyday life, light that overlays the retinal image is not recognised by the patient probably because of the low light intensity of the unfocused image. Moreover, the retinal and cortical processing of the retinal image seems to play a part leading, for example, to an improved contrast impression of the retinal image. ${ }^{34}$ The disadvantages of the multifocal principle are primarily of a theoretical nature and are attributed to the division of the incoming light between more than one focal point; but there are also clinically relevant disadvantages - for example, slightly reduced black and white contrast sensitivity, halos when looking at a bright light source by night, disadvantages in the case of a panretinal laser, and difficulties for retinal surgery. Some cases of vague discomfort, such as monocular diplopia, have also been reported. ${ }^{35}$ In our considerations we looked for a further parameter of visual quality-namely, one that can be influenced by the low light intensities that overlay the focused image in the multifocal situation. Tritan CCS was selected in the expectation it would be sensitive in patients with diabetes ${ }^{36-38}$ or chronicle glaucoma. $^{39}{ }^{40}$ Furthermore, tritan CCS can be 


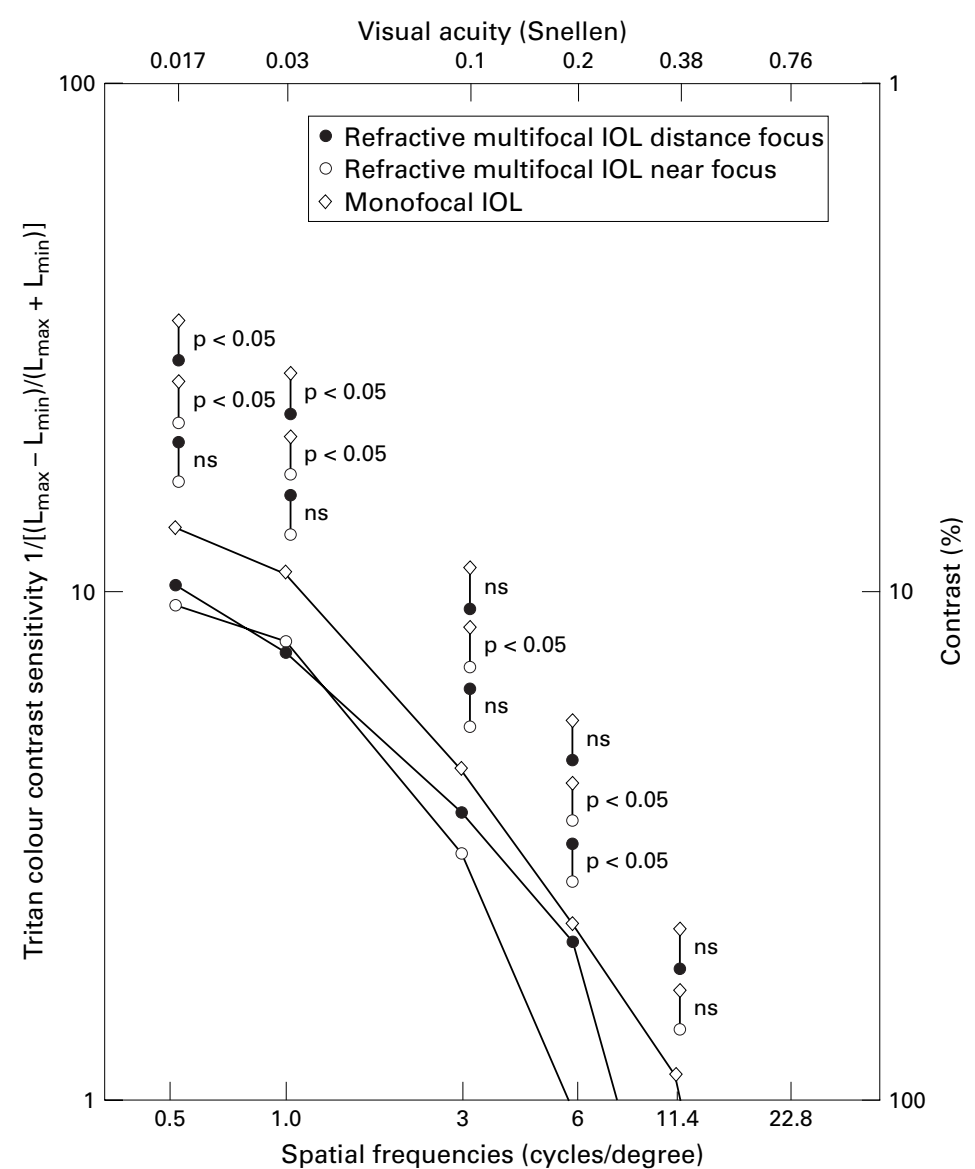

Figure 2 Colour contrast sensitivity function with glare through the distance focus $(n=$ $15)$ in a refractive multifocal IOL (Allergan $S A 40 N)$, through the near focus $(n=15)$ in a refractive multifocal IOL (Allergan $S A 40 N$ ), and in a monofocal IOL $(n=11$, Allergan SI $40 \mathrm{NB}$ ). The Mann-Whitney test was calculated between the results for the monofocal group and the distance focus of the multifocal group $(\bullet \bullet)$ ), between the monofocal group and the near focus results in the multifocal group ( -0 , and between the distance focus and the near focus results (-) in the multifocal group (ns = not significant).
The Moorfields Vision System proved easy to handle and stable. Autocalibration was performed at the beginning of each testing day and the monitor parameters had never to be changed. Flicker fusion perimetry was easy to carry out. Testing CCS turned out to be difficult with a lot of variability in the results. People who have considerable experience in CCS testing confirm that the result is affected both by the concentration of the patient and by the tear film. Closing the eyes for tear film rebuilding sometimes improves the CCS dramatically. The BAT was used in order to evaluate a possible higher sensitivity in CCS testing to glare in multifocal implants compared with monofocal implants, as reported in the literature. ${ }^{13}$

Visual acuity was comparable in both groups. All patients showed a comparable pupil reaction. It is essential to note that the pupil diameter is only $1 \mathrm{~mm}$ if the BAT is used. In view of the fact that the central $2 \mathrm{~mm}$ of the lens is mainly used for the distance focus, the lens theoretically functions as a monofocal lens using the BAT in the case of pupil diameters up to $2 \mathrm{~mm}$.

With regard to the CCS function, there are no statistically significant differences between the results in the multifocal group using the distance focus and the results for near focus (Fig 1). We had expected better results from distance focus testing because, in this lens, the light distribution provides the distance focus with more light compared with the near focus. Figure 1 also reveals worse values for the multifocal lens compared with the monofocal lens, using the distance as well as the near focus. At 0.5 the multifocal IOL reaches about $80 \%$ of the CCS function of the multifocal IOL. The differences were greater at low spatial frequencies than at high spatial frequencies and were statistically significant at $0.5 \mathrm{cpd}$ and $1 \mathrm{cpd}$. This result can be explained with the lower TFR in multifocal lenses and the highest physiological CCS at low spatial frequencies.

Using the BAT, at $0.5 \mathrm{cpd}$ the graph for CCS testing through the distance focus was slightly below the near focus graph, nearly identical at $1 \mathrm{cpd}$ and showed greater differences at $3 \mathrm{cpd}$ and $6 \mathrm{cpd}$. We had expected much worse results for the near focus graph because of the missing near power of the lens for small pupil diameters. In practice, testing using the near focus can be regarded as testing a monofocal lens blurring with minus $2.5 \mathrm{D}$ at a distance of 2 metres. It would appear that the pinhole effect, which increases the depth of focus, ${ }^{33}$ is responsible for the slight differences between the distance graph and near graph at low spatial frequencies in multifocal lenses. The differences between both graphs, that were statistically significant at $6 \mathrm{cpd}$, can be explained through the circumstance that the absence of exact refraction when testing with minus $2.5 \mathrm{D}$ becomes more relevant at higher spatial frequencies. At $11.4 \mathrm{cpd}$ and $22.8 \mathrm{cpd}$ both multifocal graphs are nearly identical owing to conditions under normal room luminance and using the BAT to reproduce the pupil diameter of tritan CCS testing with glare. 
the reduced CCS function at these spatial frequencies. The result of comparing the multifocal graphs with the monofocal graph was unexpected. At low spatial frequencies of 0.5 and $1.0 \mathrm{cpd}$ the multifocal foci reached about $86 \%$ of the CCS function of the monofocal IOL. We had considered that this multifocal lens type should have a visual function comparable to that of a monofocal lens at a pupil diameter under $2 \mathrm{~mm}$. However, this result also reconfirms results in black and white contrast sensitivity testing with the previous model of the refractive multifocal lens investigated, the AMO Array SSM 26 NB, where the central 2 $\mathrm{mm}$ was used mainly for the distant focus and partially for intermediate foci ${ }^{42}$ and also showed reduced contrast sensitivity under glare conditions compared with a monofocal lens. ${ }^{13}$ An explanation therefore might be that in this refractive lens design the central $2 \mathrm{~mm}$ do not supply the distance focal point exclusively, but also intermediate focal points, and therefore the TFR in this constellation is also reduced.

In our clinical experience, patients with multifocal lenses, including those with a monofocal lens in the contralateral eye, have never reported subjectively observed contrast deficits. It seems that the revealed differences in CCS cannot be realised under everyday light conditions but may be a disadvantage for patients with multifocal implants at low object contrasts.

1 Weghaupt H, Pieh S, Skorpik C. Visual properties of the foldable AMO Array multifocal intraocular lens. F Cataract Refract Surg 1996;22(Supp1 2):1313-17.

Refract Surg 1996;22(Supp1 2):1313-17.
2 Weghaupt H, Pieh S, Skorpik C. Comparison of pseudoacweghaupt H, Pieh S, Skorpik C. Comparison of pseudoaccommodation and visual quality between a diffractive and
refractive multifocal intraocular lens. $\mathcal{F}$ Cataract Refract refractive multifocal

3 Pieh S, Lackner B, Zöhrer R, et al. Pseudoakkommodation und Kontrastsehschärfe diffraktiver und refraktiver Multifokallinsen. In: Duncker G, Ohtloff C, Wilhelm F, eds. 12. Kongreß der Deutschsprachigen Gesellschaft für Intraokularlinsen Implantationen. Berlin: Springer, 1999:204-7.

4 Pieh S, Weghaupt H, Rainer G, et al. Visual acuity and attitude to wearing glasses after implantation of a diffractive
multifocal lens. Klin Monatsbl Augenheilkd 1997;210:3842.

5 Maxwell A, Nordan LT. Multifocal intraocular lenses. Copyright 1991 by Slack Inc.

6 Holladay J, Van Dijk H, Land A, et al. Optical performance of multifocal intraocular lenses. F Cataract Refract Surg 1990;16:413-22.

7 Eisenmann D, Hessemer V, Manzke B, et al. Modulationsübertragungsfunktion und Kontrastempfindlichkeit re-
fraktiver Mehrzonenmultifokallinsen. Ophthalmologe 1993; fraktiver $M$

8 Lang A, Portney V. Interpreting multifocal intraocular lens modulation transfers function. I Cataract Refract Surg 1993;19:505-12

9 Steinert RF, Aker BL, Trentacost DJ, et al. A prospective comparative study of the AMO ARRAY zonal-progressive multifocal silicone intraocular lens and a monofocal intraocular lens. Ophthalmology 1999;106:1243-55.

10 Walkow T, Liekfeld A, Anders N, et al. A prospektive evaluation of a diffractive versus a refractive designed multifocal intraocular lens. Ophthalmology 1997;104:1380-6.

11 Liekfeld A, Pham DT, Wollensack J. Funktionelle Ergebnisse einer neuen diffraktiven Bifokallinse versus Monofokallinse. In: Pham DT, Wollensack J, Rochels R, Hartmann C, eds. 8. Kongreß der Deutschsprachigen Gesellschaft für Intraokularlinsen Implantationen. Berlin: Springer, chaft für Intraok
12 Gimbel HV, Sanders DR, Raanan MG. Visual and refractive results of multifocal intraocular lenses. Ophthalmology results of multif

13 Pieh S, Weghaupt H, Skorpik C. Contrast sensitivity and glare disability with diffractive and refractive multifocal intraocular lenses. F Cataract Refract Surg 1998;22:659-62.

14 Rüther K, Eisenmann D, Zrenner E, et al. Der Einflu $\beta$ diffraktiver Multifokallinsen auf Kontrastsehen, Gegenlichtsehschärfe und Farbsinn. Klin Monatsbl Augenheilkd 1994; 204:14-19.

15 Olsen T, Corydon L. Contrast sensitivity as a function of focus in patients with the diffractive multifocal intraocular lens. F Cataract Refract Surg 1990;16:703-6.

16 Post CT. Comparison of depth of focus and low-contrast acuities for monofocal versus multifocal intraocular lens patients at 1 year. Ophthalmology 1992;99:1658-64.

17 Ravalico G, Baccara F, Rinalidi G. Contrast sensitivity in multifocal intraocular lenses. 7 Cataract Refract Surg 1993; 19:22-5.

18 Williamson W, Poirier L, Coulon P, et al. Compared optical performances of multifocal and monofocal intraocular performances of multifocal and mono

19 Eisenmann D, Jacobi KW. Untersuchung der Kontrastempfindlichkeit mit computergestützten Verfahren und Kontrasttafeln:vergleichende Ergebnisse bei mono- und multifokaler Pseudophakie. Akt Augenheilkd 1995;20:2015.

20 Jacobi FK, Eisenmann D. Klinische Ergebnisse der AMO Array Multifokallinse. Spektrum Augenheilkd 1996;10:53-5. Goes F. Personal results with the 3 M diffractive multifocal

22 Lindstorm RL. One-year results from 671 patients with the $3 \mathrm{~m}$ multifocal intraocular lens. Ophthalmology 1993;100: 91-7.

23 Vaquero M, Encinas JL, Jimenez F. Visual function with monofocal versus multifocal IOLs. $\mathcal{F}$ Cataract Refract Surg 1996;22:1222-5.

24 Hart William M. Adler's physiology of the eye. St Louis: Mosby-Year Book, 1992.

25 Brown PK, Wald G. Visual pigments in human and monkey retinas. Nature 1963;200:37.

26 Williams D, MacLeod DIA, Hayhoe MM. Foveal tritanopia. Vis Res 1981;21:1341.

27 Marc RE, Sperling HG. Chromatic organization of primate cones. Science 1977;196:454-6.

28 Brindles GS. The summation areas of human colour receptive mechanism at increment treshold. F Physiol (Lond) 1964;124:400

29 Farnsworth D. The Farnsworth dichotomatous test for color blindness - panel D-15. New York: Psychological Corporation, 1947.

30 Charman WN. Limits on visual performans set by eye's optics and the retinal cone mosaic. In: Kulikowski J, Walsh V, Murray IJ, eds. Vision and visual dysfunction. Limits of vision. London: Macmillan, 81-96.

31 Regan D, Tyler CW. Some dynamic features of colour vision. Vis Res 1971;11:1307.

32 Guyton D, West C, Miller J, et al. Ophthalmic optics and clinical refraction. Baltimore: Wilmer Institute, Johns Hopkins cal refraction.

33 Thal E, Miller K, Rosenthal P, et al. Optics, refraction and contact lenses. Basic and Clinical Science Course 19981999. San Francisco: American Academy of Ophthalmology,

34 Roth EH. SinnesphysiologischAspekte des Sehens mit bifokaler Intraokularlinse. In: Neuhann T, Hartmann C, Rochels R, eds. 6. Kongre $\beta$ der Deutschsprachigen Gesellschaft $265-9$.

35 Ellingson FT. Explantation of $3 \mathrm{M}$ diffractive intraocular lenses. $\mathcal{F}$ Cataract Refract Surg 1990;16:697-702.

36 Tregear SJ, Knowles PJ, Ripley LG, et al. Chromaticcontrast threshold impairment in diabetes. Eye 1997;11(Pt 4):537-46.

37 Fristrom B. Peripheral and central colour contrast sensitivity in diabetes. Acta Ophthalmol Scand 1998;76:541-6.

38 Fristrom B. Peripheral colour contrast thresholds in ocular hypertension and glaucoma. Acta Ophthalmol Scand 1997;75:376-82.

39 Porciatti V, Di Bartolo E, Nardi N, et al. Responses to chromatic and luminance contrast in glaucoma: a psychophysical and electrophysiological study. Vis Res 1997;37:197587.

40 De Jong LA, Snepvangers CE, van den Berg TJ, et al. Blueyellow perimetry in the detection of early glaucomatous damage. Doc Ophthalmol 1990;75:303-14.

41 Owlesy C, Sekuler R, Siemsen D. Contrast sensitivity throughout adulthood. Vis Res 1983;23:689-99.

42 Eisenmann D. Theoretische und klinische Abbildungseigenschaften multifokaler Intraokularlinsen mit ungleicher Gewichtung von Fern- und Nahfokus. Habilitationsschrift Giessen 1996. 